DOI: 10.2478 /ausp-2020-0015

\title{
Raising Collocational Awareness with Humour
}

\author{
Tünde NAGY \\ Sapientia Hungarian University of Transylvania (Cluj-Napoca, Romania) \\ Department of Human Sciences, Miercurea Ciuc \\ nagytunde@uni.sapientia.ro
}

\begin{abstract}
Despite the increased interest that collocations have received in EFL methodology lately, making language learners aware of these multiword constructions continues to represent a challenge for teachers. While there may be different ways of teaching collocations, finding activities that raise collocational awareness efficiently is no easy task. Collocational awareness can be defined as the ability of language learners (and users) to use and acknowledge word combinations in their entirety. Humour can be useful in this regard as it not only ensures a more relaxed atmosphere in the classroom but can also help students to acknowledge and remember specific linguistic structures (among them, also collocations) more easily. In line with Construction Grammar (Goldberg 1995, 1997, 2006), it is believed that collocations are to be treated as constructions, pairings of form with a specific meaning and varying degrees of predictability - teaching them as such can contribute to a better understanding and acquisition of these constructions. After offering a brief overview of the characteristics of collocations and reflecting on the possible advantages of using humour in class, the paper shows possible ways of teaching collocations with humour. The exercises and activities suggested focus on both the productive and receptive competence of language learners and also incorporate the necessary skills required in the language learning process: listening, reading, writing, and speaking.
\end{abstract}

Keywords: collocations, constructions, humour, teaching, collocational awareness

\section{Introduction}

When teaching vocabulary, attention should be given not only to the possible meanings a word has but also to the context in which the word appears. Despite the difficulties that teaching collocations implies (high number and different types of collocations to choose from), introducing collocations to students brings along a series of advantages such as vocabulary improvement, greater fluency, and the increased ability of students to communicate even with limited lexical and 
grammatical knowledge. Ideally, collocations should be taught at all levels and age-groups to help language learners develop collocational competence right from the start and make them aware of the differences between languages (especially important in the case of negative transfer from L1). Even though all exercises and activities related to collocations may impact students' vocabulary positively, the ones that show them in their entirety as constructions are believed to be the most beneficial for students. In addition, incorporating some humour in foreign language classes (due to the complex nature of humour, sometimes possible only in more advanced classes) can increase students' interest in the lesson and motivate them to take part in classes more actively. As such, an important question this paper raises is how different types of humour can be used to teach collocations in EFL classes.

\section{What are collocations?}

Collocations can be considered more or less entrenched word combinations that appear frequently together. The term itself comes from the Latin collocare (co - together + locare (locus - place) meaning "place together") expressing "the relationship a lexical item has with other items that appear with greater than random possibility in (its) textual context" (Hoey 1991: 6-7). It is "the co-occurrence of two or more words within a short space of each other in a text" (Sinclair 1991: 10). Due to their great variety and complexity, it is not an easy task to give a precise definition of these constructions, so that no exact definition of collocations can be found as of yet. One important characteristic of collocations is that they are halfway entrenched constructions (Schmid 2003: 235) whose constituent elements may or may not be interchangeable or separated by additional words. The number of collocations with interchangeable elements is high: consider, for example, large/big/huge problem or give/deliver/hold a lecture with only a slight difference between them; whereas some of these constructions allow for additional elements to be inserted (e.g. deliver an interesting lecture, pay close attention, etc.), this is not possible in the case of more fixed constructions, lexical bundles such as by and large, safe and sound, peace and quiet, etc. Regarding their predictability, idiomaticity, and combined recurrence, collocations can be found halfway between free syntactic combinations and fixed expressions (Schmid 2003: 235). In addition, they represent cases of gradience, ranging from more prototypical (recurrent binary) constructions, such as pay attention (verb + noun phrase), slight problem (adjective + noun phrase), etc., to less typical constructions (that include prepositions and other function words) such as run out of something (verb phrase + prepositional phrase).

Collocations can be either lexical or grammatical depending on the part of speech the constituent elements belong to (Benson et al. 1986). Lexical collocations contain combinations of lexical categories such as verb + noun (run a program), noun + 
verb (plane takes off), verb + adverb (argue heatedly), adjective + noun (rancid butter), adverb + adjective (hopelessly devoted), or noun + noun (comfort zone). Grammatical collocations are different from lexical ones in that they contain a preposition (e.g. noun + preposition (attitude towards), preposition + noun, e.g. by accident, in advance), a to-infinitive, or a that-clause (such as to be ready to (predicative adjective + to infinitive), to be afraid that (adjective + that clause), etc.).

From a semantic point of view, collocations are made up of the base that bears most of the meaning of the construction and a collocator (McKeown and Radev 2000). The base can either select for several collocators (e.g. in case give/deliver/present a lecture, the base (lecture) appears with multiple collocators) or only one specific collocator, e.g. in the construction commit a suicide, suicide as the base only selects for the collocator commit. In some other cases, the collocator itself can be semantically empty; for example, in the construction take a bath, take does not add any additional meaning to the construction other than have (McKeown and Radev 2000) although it alters its aktionsart category, focusing on the end result of the activity rather than the activity itself. Though often included in the same category with idioms, collocations are semantically more analysable than idioms are. Occupying a mid-position between free combinations and fixed constructions, collocations vary with respect to compositionality and transparency (e.g. make progress is a transparent collocation, whereas run a program has a more idiomatic meaning). In this paper, collocations will be understood as constructions, pairings of form with a specific meaning, as understood by Goldberg (1995, 1997, 2006). In line with her understanding of constructions, collocations are seen as building blocks of language, as symbolic units with independent semantic and syntactic properties and with varying degrees of fixedness and frequency. Their meaning results from the integration of the meaning of the component elements with the meaning of the construction as a whole.

\section{Why teach them?}

Teaching collocations in EFL classes can be beneficial for all age-groups and at all levels. Introducing them not only in more advanced classes but already at elementary level has its advantages as this way students can get used to seeing and learning word combinations right from the start. As Antle (2013) notes, learning collocations at lower levels helps language learners to use their skills productively, without having to know much vocabulary or grammar. The same idea is put forward by Shin and Nation (2008), who provide a list of the most frequent collocations in English based on electronic corpus data (BNC). The list contains both lexical and grammatical collocations and is suitable for elementary level and upwards.

With regard to more advanced levels, an important reason for teaching collocations is to increase language learners' fluency and native-like selection 
(Shin and Nation 2008: 340). Many experts in the field, among them Waller (1993) and Kjellmer (1991), point out the correlation between language proficiency and the knowledge of collocations, which they see as the marker of native-likeness. According to Waller (1993), although advanced learners might sound native-like, their insufficient knowledge of collocations is a tangible marker of their nonnativeness. Demir (2017) notes that intermediate-level students are too dependent on the structures they have acquired before, using mainly individual words instead of chunks of language. The similar idea is expressed by Kjellmer (1991), according to whom language learners tend to struggle with collocations due to the fact that they are used to seeing and learning words separately without their context. Teaching collocations to students (e.g. the ones related to the topics in class) can help them to get used to learning and also to using word combinations and strings of words and at the same time to get familiar with the lexical and grammatical specifics of native language use. It can also help them to formulate their ideas more precisely, as Howarth (1998) notes. An interesting observation of his is that, although advanced learners often show a good knowledge of restricted collocations and semi-idioms, having internalized them successfully, they might struggle with medium-strength collocations (where the base can select for some collocators but disallow others). According to him, this is the area where teachers should invest the most in when trying to teach collocations to language learners (Howarth 1998: 42).

Finally, in addition to improving language learners' vocabulary, word combinations and chunks of language are also believed to help students learn grammar (consider Antle 2013 and Hill 2000). Antle (2013) remarks that a more lexical approach that presents grammatical structures within chunks of language could be more efficient than gap-fill exercises, where the correct word needs to be filled in the gaps. The reason behind this is that with gap-fill exercises students tend to concentrate on parts of a construction rather than remember it as a whole. Creating exercises that present grammatical constructions in their entirety often requires some creativity and planning from the part of the teacher, especially as gap-fill type exercises prevail in language course books. Nevertheless, it is considered that combining such exercises with activities that allow for the practice of a linguistic structure as a whole can yield better results as far as the acquisition and proper use of constructions are concerned.

\section{Humour as an instructional tool}

Crawford (1994: 66) defines humour as a "dynamic symbolic act that links people", "a verbal or non-verbal activity eliciting a positive cognitive or affective response from listeners". The understanding of humour (e.g. the conditions under which it is considered appropriate, the reactions to instances of humour) depends on cultural and social beliefs and also practices (Sen 2012). Humour can be classified 
on the basis of a variety of factors, such as the medium of communication, style (e.g. farcical versus tragi-comical), and formal structure (for example, miming, standup comedy) (Davies 2013: 1), and includes a variety of forms (such as anecdotal, blue, burlesque, dark humour, dry humour, parodic, satirical, self-deprecating, situational, ironic, visual humour and practical jokes (e.g. pranks), etc.). Research on humour has given rise to several theories of humour such as the Relief Theory (which focuses on the role of humour to release tension and anxiety), the Incongruity Theory (according to which humour results from the incongruity with an expected pattern), Superiority Theory (stating that humour leads to a sense of triumph or of victory) (Meyer 2000: 310), and also the Instructional Humour Processing Theory (related to the use of humour in educational settings).

The idea of using humour in EFL classes is relatively new, being present in EFL methodology since the 1980s (Bilokcuoglu and Debreli 2018: 358); nevertheless, there is already a vast literature on incorporating humour in teaching practices. Many studies (Abu Bakar 2018; Bilokcuoglu and Debreli 2018; Forman 2016; Bell 2005, 2009; Wanzer et al. 2006, to name just a few) point out the fact that applying humour in teaching can bring along a series of benefits that can be psychological (like relieving stress and anxiety), social (improving the teacher-student relationship), and also instructional (enhancing comprehension and subject recall). In addition, as Alexander (1997: 180) as well as Ziyaeemehr and Kumar (2014: 11) note, humour can be used to introduce language learners to the cultural aspects of a specific language and also to sensitize them with untranslatable jokes, idioms, and fixed expressions.

In order to apply humour effectively in the classroom, however, there are a few things that should be taken into consideration. First, there is a difference between good humour and negative humour (Banas et al. 2010). Riddles, funny stories, jokes, puns, cartoons, and riddles can be considered examples of good humour, while sarcasm, humour with a sexual, racist, or ethnic undertone or aimed at disparaging students (intellectually or in a way that they might find personal) classify as negative humour. It might seem that each type of humour can be classified either as positive or negative. Nevertheless, there is also an overlap between the categories; therefore, for example, sarcasm, though in most cases classified as negative, can in some cases be considered as appropriate for teaching (Torok et al. 2004).

An important criterion when using humour for pedagogical purposes is that of effectiveness, which is very much linked to appropriateness (Bell 2009, Banas et al. 2010). Bell (2009) considers humour effective if it matches the personality of the teacher and also if it is appropriate to the context and situation. Appropriateness can also be defined with respect to timing (humour used at different times in the class can serve distinctive purposes), relatedness to content (content-based humour), and everyday life experiences (Abu Bakar 2018). It often functions as a starting point for describing types of humour. Wanzer et al. (2006), for example, make a distinction between appropriate and inappropriate humour and include in the first 
category humour that can be either related or unrelated to the lesson content (such as jokes, humorous stories and performances, funny role plays and activities), selfdisparaging humour (the teacher making fun of him-/herself, sharing embarrassing stories, making fun of his/her abilities), and unintentional or unplanned humour (when the teacher spontaneously incorporates humour in class). On the other hand, sexual jokes and comments, sarcasm, morbid humour (on the part of the teacher), and disparaging humour (where students as targets are ridiculed either because of their intelligence, gender, or appearance) are examples of inappropriate humour.

The Instructional Humour Processing Theory (IHPT) developed by Wanzer et al. (2010) also uses appropriateness as a key concept along with the notion of relevance. The theory is meant to illustrate the relationship between instructional humour and learning, and it is based on the idea that humour can facilitate learning and at the same time increase content recall in case it is appropriate and relevant (Banas et al. 2010: 119). The two concepts are considered equally important: the former ensures a positive atmosphere enabling students to process the information heard, and the latter (referring to its content-relatedness) makes the information more memorable (Banas: 119). According to IHPT, content-related humour correlates well with student learning, affecting the motivation of students and their ability to process in a positive way.

Using humour in the classroom is never risk-free, so that, regardless of its type and the intent behind it, humour may not be as effective as expected. Humour is quite a complex phenomenon, so that what is found humorous or funny by the teacher may not be seen as such by the students (Abu Bakar 2018); besides, there is also the risk of overusing it (Abu Bakar 2018: 61). Bolkan et al. (2018) believe that integrated humour (in the form of explanatory examples) may also be counterproductive. The reason for it is that integrated humour tends to be more memorable than the concept being taught, and this may result in students recalling the humorous comment instead of the content itself. Taking this into consideration, it is highly recommended that humour be used with moderation in the classroom and also be completed with other activities that enable a more in-depth practice of the linguistic structures in question.

\section{Teaching collocations with humour}

In the light of the above, the question arises as to how humour can be used to teach collocations. It is considered that humour in general can be effective for teaching collocations as long as it helps students in their language learning process (in which case humour is considered appropriate and relevant). Forms of verbal humour (such as wordplay, homonyms, and figurative speech) are considered especially useful in this regard as they direct students' attention to the constructions in question. The 
advantages of incorporating verbal humour in EFL classes have been acknowledged by many experts in the field. Alexander (1997: 186), for example, remarks that forms of verbal humour, such as jokes, misprints, and riddles, do not only enliven the atmosphere in class but also come in handy for teaching students linguistic constructions, among them, also collocations. Verbal humour conveys the linguistic and cultural specifics of the target language, and as a consequence it can be highly beneficial for language learners (Ziyaeemehr et al. 2011: 114). Ziyaeemehr and Kumar (2014: 3) define three important functions of verbal humour in teaching practices: foregrounding, reinforcing meaning, and highlighting cultural dissimilarities. According to them, verbal humour can be used as an instructional strategy to foreground specific linguistic structures. In addition, it can reinforce the knowledge of a linguistic structure and at the same time expand language learners' linguistic and cultural knowledge.

In agreement with Ziyaeemehr and Kumar (2014), verbal humour is expected to have multiple functions: by offering something contrary to expectation (where the humorous element results from), verbal humour directs students' attention to a specific construction. Doing so, it can lead to an increased linguistic and cultural awareness and a more entrenched use of constructions provided that students have already been familiar with it. In addition to verbal humour, other sources of humour, such as funny texts and pictures (where the humorous effect does not necessarily result from linguistic elements), can also be effective for teaching collocations. In this case, it is often necessary that the teacher draw students' attention to specific constructions either by highlighting them in the text or writing them on the whiteboard (thereby applying an explicit teaching method). Furthermore, it is believed that humour is best used as a starting point for discussions or in combination with other types of exercises to enable students to observe collocations in several different contexts. As a consequence, they can gain a more in-depth understanding of these constructions.

In what follows, a few ideas will be given of how different types of humour (verbal humour, visual humour, and also other humorous materials) can be used for teaching collocations in the EFL classroom. Activities that present collocations in their entirety as constructions have been preferred over the ones that focus on parts of collocations (such as matching and gap-fill exercises).

\subsection{Humorous exercises and activities for teaching collocations}

Forms of verbal humour, such as puns and riddles that are based on wordplay, can be very effective as teaching materials as they can contribute to a more increased collocational awareness by directing students' attention to a particular construction. They are usually applicable in more advanced classes as the language of riddles often contains idiomatic phrases, homonymy, and/or polysemy that are hard to understand for lower levels. The puns below can be used to complement 
the teaching material related to travelling. A possible way of using them for the practice of collocations is as follows: the teacher makes a copy of the puns for each student in the class (the students will work in pairs or small groups). They will have the task to find the humorous element in the sentences (estimated time: 5 to 10 minutes) and then classify the sentences with respect to how humorous they are ( 1 - the funniest, 10 - the least funny). In the end, the teacher will make sure that all students have understood the comical element in the puns.

'I've just arrived in Bulgaria'. 'How is it?' 'Sofia, so good.'

'Ever thought about how funny mountains are? They're hill areas.'

'I've heard Oslo is a particularly dangerous city. There's Norway I'd ever go.'

'My friend was struggling to sleep in Stockholm. I wished her Swede dreams.'

'I had an instant connection with someone in South Korea. I think they're my Seoul mate.'

'My girlfriend went for a short break to the Caribbean. "Jamaica?" "No. She went of her own accord.'

'My cousin didn’t expect to like Cuba. Turns out she's Havana great time.'

'I'm not sure where to find snow in America. Alaska local.'

'The sun only took one hat and a t-shirt on his holiday. He was travelling light.'

'Sophie Ellis Bextor killed a man in a club in Poland. It was murder on Gdansk floor.'

(Source: https://mpora.com/travel/31-travel-puns-bad-theyll-make-friendsfamily-leave/\#p1yBSjQmJ4VIAUmH.97)

Similar to puns, riddles often provoke laughter in the classroom and also represent an equally useful tool when it comes to raising language learners' awareness of collocations.

A "Guess the answer" worksheet, where students need to guess the answers to riddles, can be a fun activity that language learners will most probably enjoy. A sample of such a worksheet can be found in Appendix 1. It comprises two parts: the first part contains riddles with clues given in the brackets to help students guess the answer, and the second part consists of a brainstorming activity asking students to come up with constructions containing the words given (in some cases, there might be more than one possible answer). The activity can be done either as pair work or in small groups; estimated time: 15 to 20 minutes. After all possible answers are discussed (as a whole-class activity), the teacher can ask students questions about their general preferences and experiences, using some of the collocations discussed beforehand. This then brings along the advantage of not only making students more familiar with the collocations in question but also of learning more about each other. 


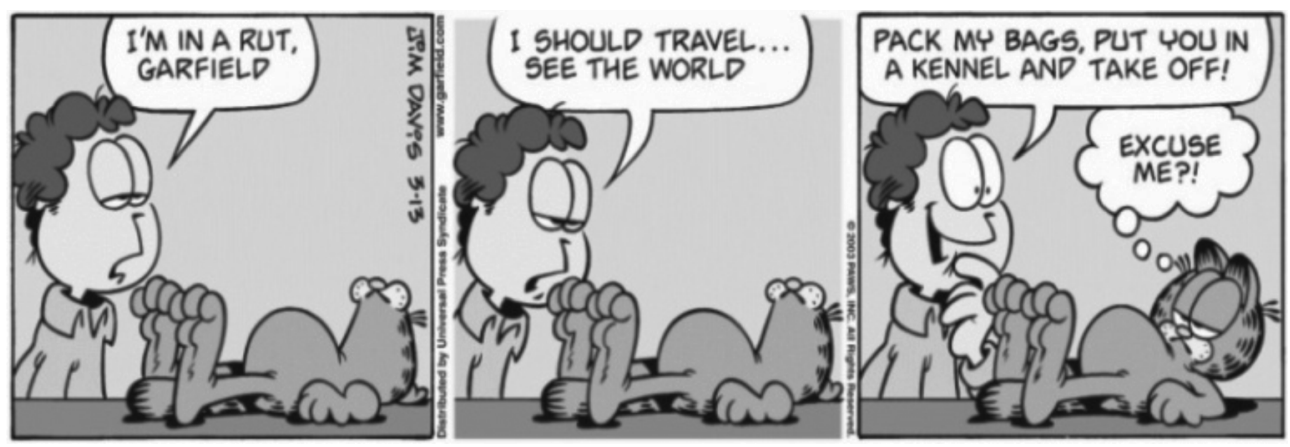

Source: https://garfield.com/comic/2003/03/13

Figure 1. Cartoon captions
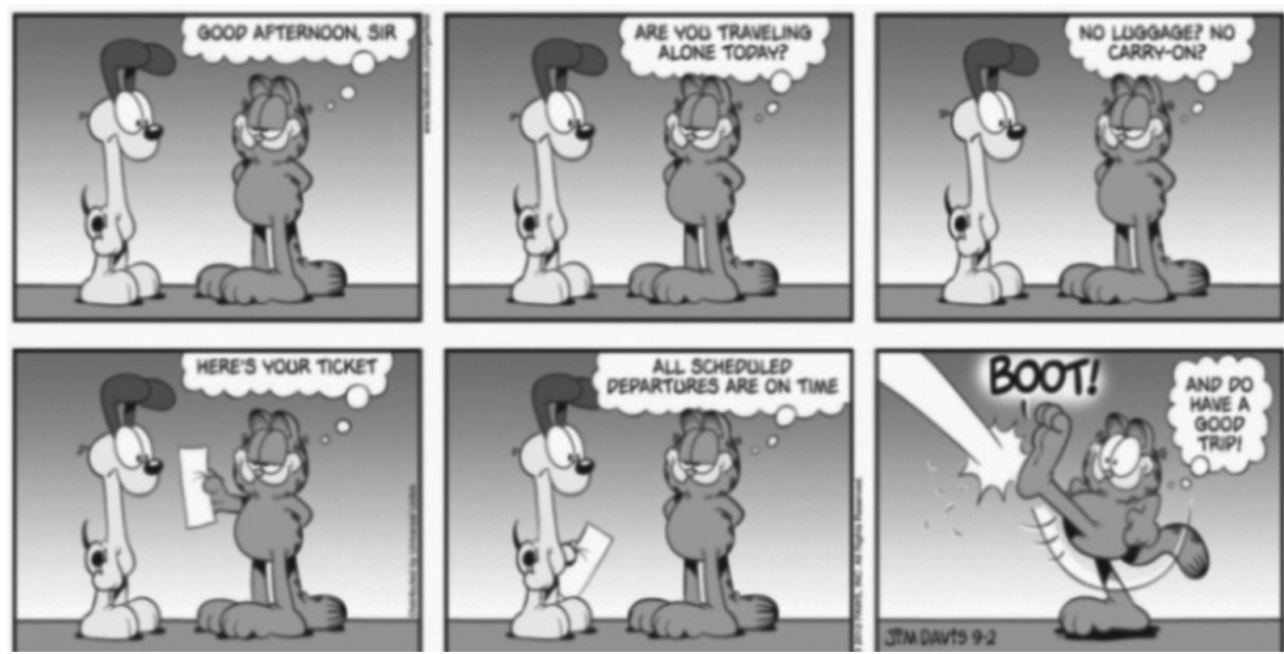

Source: https://garfield.com/comic/2012/09/02

Figure 2. Cartoon captions

Other humorous ways of teaching collocations include the use of comic strips (e.g. Garfield, Calvin and Hobbs, the Simpsons, etc.), humorous picture stories and texts (anecdotes). Comic strips represent a mix of visual and verbal humour, are fun, versatile, and visually motivating for students. As they contain small chunks of language, they are ideal for teaching collocations even for lower levels. The comic strips above are also related to travelling and can be used as an introduction to the topic from pre-intermediate level upwards. The activity can be done as follows: the teacher makes a copy of the captions for each student in the class and checks whether the students are familiar with the register used (e.g. the idiom be in $a$ rut, the word combinations put in a kennel, take off, carry-on luggage, scheduled departures, etc.). Then the students (working in small groups) choose either the 
first or the second set of pictures and write a background story for it (around 15 to 20 minutes). After the students have finished, they read their story out loud to each other (whole-class activity). As the next step, the teacher may ask students about their travel experiences by using some of the collocations found in the captions (e.g. travelling alone, packing one's bags, be on time, seeing the world) (10 to15 minutes).

The teacher can also give funny picture stories to students and ask them to write captions for them (ideal for small groups of three to four students). Depending on the picture story, the activity can be carried out at various levels. It is advisable to choose a picture story that is related to the topic of the lesson (e.g. the pictures below are related to travelling) and where several captions are needed as this gives more room for students to be creative. In order to put collocations in focus, the teacher will write a few collocations (not more than five and not necessarily related to the story) on the whiteboard and ask students to include them in the captions. As a follow-up activity, students read their captions to each other. Alternatively, the teacher can give students only one frame at a time, rather than presenting the entire story, and make students anticipate what happens next and how the story might end. The activity is expected to take around 20 to 25 minutes, also depending on the level of the class (less time for more advanced students).

Another version of the activity is to hand out the entire picture story and ask students to write the narrative and also to finish the story to their liking by adding an imaginary last frame to the tale. As in the previous activity, students will be given a handful of collocations to use in their storytelling. Once the students have written the story, they read it out loud to each other (around 20 minutes).
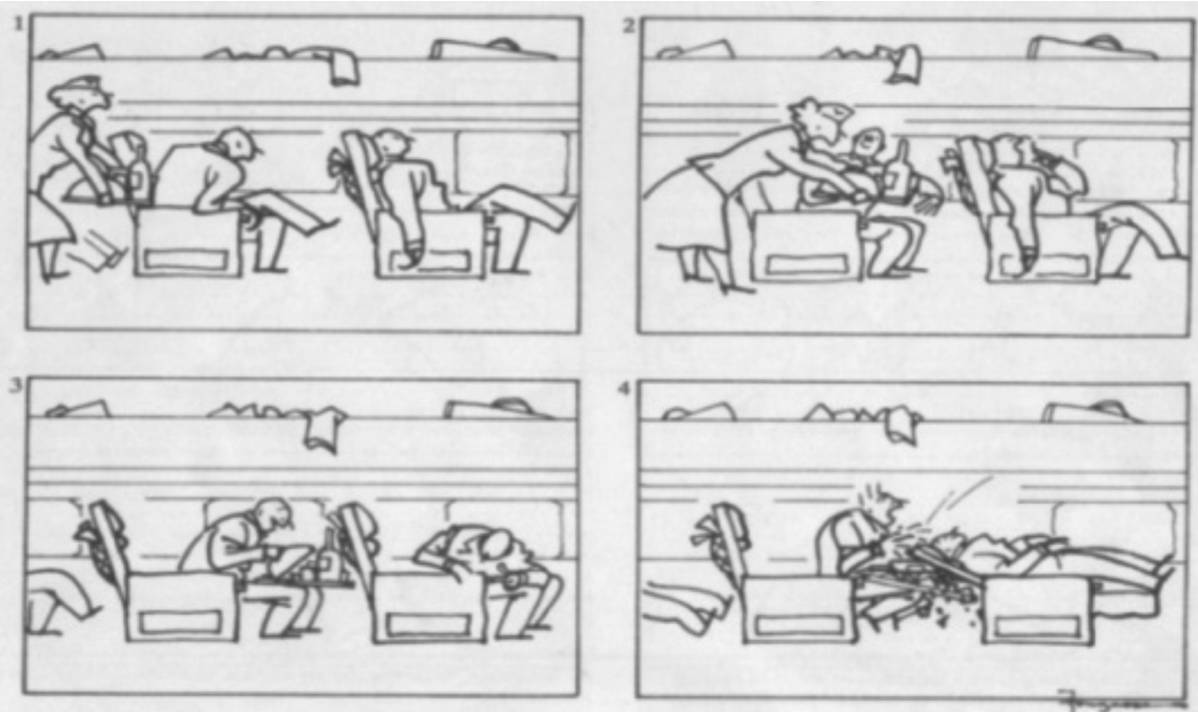

Source: https://peterviney.wordpress.com/about/fougasse-picture-stories/

Figure 3. Picture story 
The anecdote below is an example of humorous texts appropriate for teaching collocations in the classroom. It describes the funny situation of meeting your looka-like while travelling, a situation that also serves as a good topic for preceding discussions. Thus, before reading the anecdote, the teacher can ask students to work in pairs and discuss the hypothetical situation of meeting a doppelganger (how they would feel, what they would do, etc.), for about 10 minutes; the activity itself is suitable for intermediate and advanced learners due to the register found in the text. Then the teacher hands out the anecdote to the students with some (or, if the story is short, all) collocations highlighted in them. The teacher can ask students to give a synonym or a short explanation of the highlighted collocations and then compare the situation described to their own imaginary situation (estimated time: 5 to 10 minutes).

\section{Bearded man meets doppelganger on plane Neil Thomas Douglas encounters stranger with whom he shares an uncanny resemblance on flight to Galway}

A man has spoken of the "total weirdness" of encountering his doppelganger after boarding a flight and finding him sitting in his seat. Neil Thomas Douglas, a photographer from Glasgow, was travelling to Galway via Stansted on Thursday night when he came face to face with the bearded stranger.

Douglas said: "When I got on the Ryanair flight, there was a dude already on my seat - when the guy looked up, I thought: 'He looks like me.' We had a big laugh about it - everyone around us had a laugh, we took a selfie and that was it." But the pair were later to encounter a further coincidence when they checked into the same hotel in Galway. Douglas said: "Later that night, I went to the pub and again, there was my twin. Total weirdness. We had a laugh and a pint." Source: https://www.bbc.com/news/uk-scotland-34679496

In addition to written humorous texts, like anecdotes and jokes, audiovisual texts can also be suitable for practising collocations. Students generally love watching movies, so a funny short film will most probably be to their liking; it is advisable to choose a movie that does not exceed 5 minutes lest it should take up too much time from the class. The movie below (duration: 3 min. 12 sec.) shows the situation of two flight attendants giving safety instructions on a plane and making funny movements as a reaction to the pilot's words (hilarious in themselves). The movie serves as a good starting point for discussions about flying, and there are a couple of topic-related collocations in the video that the teacher can write on the whiteboard to help students tackle the topic and also to talk about their travelling experiences (intermediate level and above due to the register used; duration: around 20 minutes): https://www.youtube.com/watch?v=4BuOlKZ_C2k. 
In the case of lower-level classes, the teacher may opt for a silent short movie as they are often more widely applicable. In the short movie below (duration: 3 min. 45 sec.), there are three characters: a man who steals a woman's purse, another man who catches him in action, and the woman herself. The movie is enjoyable, dynamic and also has a twist at the end. After watching it, the students will be asked to retell the story in their own words (whole-class activity, around 10 minutes); subsequently, the teacher can choose a scene from the film (e.g. the last one) and ask the students to imagine and write down what the characters might be thinking (best done as a pair-work activity). Eventually, the students can exchange their ideas in smaller groups (5 to 10 minutes). Even in the case of more advanced classes, it is advisable that the teacher write some useful collocations related to the story on the whiteboard prior to the activity. This activity will require some creativity on the part of the students and might take up more time than indicated, depending on the level of the group: https://www.youtube.com/watch?v=plrj-JUieYE.

\section{Conclusions}

Humour can serve both to enliven the atmosphere in EFL classes and as an important teaching tool. Incorporating verbal humour, such as jokes, puns, riddles, and wordplays, and also using other humorous resources (like written and audio-visual texts, picture stories) in the classroom can bring a series of advantages as far as the collocational awareness and cultural sensitivity of students are concerned. Forms of verbal humour can be considered an effective teaching tool, especially as they put the focus on particular constructions; in the case of other humorous materials, it is advisable that the teacher apply an explicit teaching method by drawing students' attention to these constructions. There are various ways of doing this, such as highlighting linguistic structures in the text or writing them on the whiteboard. The exercises and activities described give examples of how humour can be used to teach lexical and grammatical collocations to students. Due to the complex nature of humour and the skills required to understand it, humorous exercises and activities are usually more suitable for advanced classes. Nevertheless, they may also be adapted to the needs of lower-level students. Furthermore, as it has been pointed out, regardless of its type and the intent behind it, the use of humour in the classroom is not always risk-free. As a consequence, it is advisable that humour be used as part of warm-up activities or supplementary exercises that complement the lesson material. 


\section{References}

Abu Bakar, Farhana. 2018. The Use of Humour in Teaching and Learning in Higher Education. https://ourarchive.otago.ac.nz/handle/10523/8238 (Last accessed: 14 August 2020).

Alexander, R. Richard.1997. Aspect of Verbal Humour in English. Tübingen: Gunter Narr Verlag.

Antle, Joshua Brook. 2013. Teaching collocations. In Nozomu, Sonda-Aleda Krause (eds), JALT Conference Proceedings 2012, 346-354. Tokyo: JALT.

Banas, A. John-Norah Dunbar-Dariela Rodriguez-Shr-Jie Liu. 2010. A review of humor in educational settings: Four decades of research. Communication Education 60(1): 115-144.

Bell, D. Nancy. 2005. Exploring L2 language play as an aid to SLL: A case study of humour in NS-NNS interaction. Applied Linguistics 26(2): 192-218.

- 2009. Learning about and through humor in the second language classroom. Language Teaching Research 13(3): 241-258.

Benson, Morton-Evelyn Benson-Robert Ilson. 1986. The BBI Combinatory Dictionary of English: A Guide to Word Combinations. Amsterdam-Philadelphia: John Benjamins.

Bilokcuoglu, Hasan-Emre Debreli. 2018. Use of humour in language classes: An effective 'filter' for affective filter? Journal of Language and Linguistic Studies 14(3): 347-359.

Bolkan, San-Darrin J. Griffin-Alan K. Goodboy. 2018. Humor in the classroom: The effects of integrated humor on student learning. Communication Education 67(2): 144-164.

Crawford, C.B. 1994. Theory and implications regarding the utilization of strategic humor by leaders. The Journal of Leadership Studies 1(4): 53-68.

Davis, Jessica Milner. 2013. Humour and its cultural context. In Jessica Davis Milner-Jocelyn Chey (eds), Humour in Chinese Life and Culture: Resistance and Control in Modern Times, 1-21. Hong Kong University Press.

Demir, Cüneyt. 2017. Lexical collocations in English: A comparative study of native and non-native scholars of English. Journal of Language and Linguistics Studies 13(1): 75-87.

Forman, Ross. 2016. First and Second Language Use in Asian EFL. Bristol: Multilingual Matters.

Goldberg, E. Adele. 1995. A Construction Grammar Approach to Argument Structure. Chicago: The University of Chicago Press.

- 1997. The relationships between verbs and constructions. In Verspoor, MarjolijnLee KeeDong-Eve Sweetser (eds), Lexical and Syntactical Constructions and the Construction of Meaning, 383-399. Amsterdam-Philadelphia: John Benjamins.

- 2006. Constructions at Work. Oxford: Oxford University Press. 
Hill, Jimmie. 2000. Revising priorities: From grammatical failure to collocational success. In Michael Lewis (ed.), Teaching Collocation: Further Developments in the Lexical Approach, 47-67. Hove: LTP.

Hoey, Michael. 1991. Patterns of Lexis in Text. Oxford University Press.

Howarth, Peter. 1998. Phraseology and second language proficiency. Applied Linguistics 19(1): 24-44.

Kjellmer, Göran. 1991. A mint of phrases. In Karin Aijmer-Bengt Altenberg (eds), English Corpus Linguistics. Studies in Honour of Jan Svartvik, 111-127. LondonNew York: Longman.

Mckeown, Kathleen R.-Dragomir R. Radev. 2000. Collocations. In Robert DaleHerbert Moisl-Herbert Somers (eds), A Handbook of Natural Language Processing, 507-523. New York: Marcel Dekker.

Meyer, C. John. 2000. Humor as a Double-Edged Sword: Four Functions of Humor in Communication. Communication Theory 10(3): 310-331.

Nesi, Hilary. 2012. Laughter in university lectures. Journal of English for Academic Purposes 11(2): 79-89.

Schmid, Hans-Jörg. 2003. Collocations: Hard to pin down, but bloody useful. Zeitschrift für Anglistik und Amerikanistik 51(3): 235-258.

Sen, Anindya. 2012. Humour analysis and qualitative research. Social Research Update 63 https://sru.soc.surrey.ac.uk/SRU63.pdf (Last accessed: 14 August 2020).

Shin, Dongkwang-Paul Nation. 2008: Beyond single words: The most frequent collocations in spoken English. ELT Journal 62(4): 339-348.

Sinclair, John. 1991. Corpus, Concordance, Collocation. Oxford: Oxford University Press.

Torok, E. Sarah-Robert McMorris-Lin Wen-Chi. 2004. Is humor an appreciated teaching tool? Perceptions of professors' teaching styles and use of humor. College Teaching 52(1): 14-20.

Waller, Tove. 1993. Characteristics of near-native proficiency in writing. In Ringbom Hakan (ed.), Near-Native Proficiency in English, 183-293. Finland: Abo Akademi. Wanzer, Melissa Bekelja-Ann Frymier Bainbridge-Ann Wojtaszczyk-Tony Smith. 2006. Appropriate and inappropriate uses of humor by teachers. Communication Education 55(2): 178-196.

Wanzer, Melissa Bekelja-Ann Frymier Bainbridge-Jeffrey Irwin. 2010. An explanation of the relationship between instruction humor and student learning: Instructional Humor Processing Theory. Communication Education 59(1): 1-18.

Ziyaeemehr, Ali-Vijay Kumar. 2014. The role of verbal humor in second language education. International Journal of Research Studies in Education 3(2): 3-13.

Ziyaeemehr, Ali-Vijay Kumar-Mohd S. Faiz Abdullah. 2011. Use and non-use of humor in academic ESL classrooms. English Language Teaching 4(3): 111-119. 


\section{Appendix 1. Worksheet on collocations}
Jokes
Jokes
Jokes
Jokes
Jokes

(-):-(:)

1. What's the best thing about Switzerland? I don't know but the flag is a . (something extra)

2. Did you hear about the mathematician who is afraid of negative numbers? He will stop ___ to avoid them. (have no break)

3. Did you hear about the new restaurant called Karma? There is no menu: you get what you . (is meant for you)

4. Did you hear about the claustrophobic astronaut? He just needs a . (small area)

5. What don't scientists trust? Because they everything. (invent)

6. What sits at the bottom of the sea and twitches? A (person suffering from stress and mental exhaustion)

7. What's the astronaut's favourite part on a computer? The (type of bar)

8. What do you get from a pampered cow? . (liquid gone bad/ sour)

9. I always knock on the door before opening, just in case there is a . (on the top of vegetables).

10. Why are ghosts such bad liars? Because they are easy to (transparent)

11. Why did the gym close down? It just didn't (function)

12. I tried to sue the airport for misplacing my luggage. I (didn't find my bag).

2. What words (Verbs, Prep., Adj., Adv.) go with:

Laugh:

Smile:

Joke:

Key:

Ex. 1: big plus, at nothing, deserve, little space, make up, nervous wreck, space bar, spoiled milk, salad dressing, see through, work out, lost my case.

Ex. 2: Several possibilities (online sources: http://www.freecollocation.com/, http:// www.ozdic.com/collocation-dictionary/joke, https://inspirassion.com/en/). 